\title{
Transient Analysis and Stability Limits for Synchronous Reluctance Motors Considering Saturation Effects
}

\author{
M. N. Ibrahim ${ }^{1,2}$, Student Member IEEE, E. M. Rashad ${ }^{3}$, SMIEEE and P. Sergeant ${ }^{1}$, Member IEEE \\ ${ }^{1}$ Department of Electrical Energy, Systems and Automation, Ghent University, Ghent B-9000, Belgium \\ ${ }^{2}$ Electrical Engineering Department, Kafrelshiekh University, Kafrelshiekh, Egypt \\ ${ }^{3}$ Electrical Power and Machines Department, Tanta University, Tanta, Egypt \\ E-mail: m.nabil@eng.kfs.edu.eg
}

\begin{abstract}
This paper investigates the influence of the magnetic saturation on the transient performance of Synchronous Reluctance Motors (SynRMs). In addition, the stability limits for the SynRM are studied using a more accurate model. The saturation, cross-saturation and position effects on both direct $(d)$ and quadrature $(q)$ axis flux linkages are considered. A Finite Element Method (FEM) is used to obtain an accurate representation for the $d q$-axis flux linkages relations. In order to reduce the calculation time of the finite element analysis, a look-up table (LUT) for the $d q$-axis flux linkages is generated based on the FEM to be used for simulating the SynRM characteristics. It is found that the magnetic saturation in the adopted motor results in an enlarged region of stable operation of the SynRM. The torque increases by about $200 \%$ compared with the unsaturated case, which proves that it makes no sense to model this type of motor without saturation. The results show the importance of including the saturation factors on the performance of the SynRM and its stability limits. Hence, the magnetic saturation effect will not only affect the stability of the motor but also on the whole drive system.
\end{abstract}

Index Terms - FEM, Magnetic Saturation, Stability Limits, Synchronous Reluctance Motor.

\section{NOMENCLATURE}

$\begin{array}{ll}i_{d}, i_{q} & \begin{array}{l}\text { Instantaneous direct and quadrature axis stator } \\ \text { current respectively, A }\end{array} \\ L_{d}, L_{q} & \begin{array}{l}\text { Direct and quadrature axis stator inductance } \\ \text { of SynRM respectively, } \mathrm{H}\end{array} \\ P & \text { Number of pole pairs } \\ p & \text { Differential operator }(\mathrm{d} / \mathrm{dt}) \\ R_{s} & \text { Stator resistance of SynRM, } \Omega \\ T_{e} & \text { Electromagnetic torque of the motor, N.m } \\ v_{d}, v_{q} & \text { Instantaneous direct and quadrature } \\ V_{m} & \text { component of stator voltage respectively, V } \\ I_{m} & \text { Maximum input voltage of the motor, V } \\ \delta, \alpha & \text { Maximum input current of the motor, A } \\ \omega_{r}, \omega_{s} & \text { Load angle and current angle, rad } \\ \theta_{r} & \text { Motor and synchronous speed, rad/s } \\ \lambda_{d}, \lambda_{q} & \text { Rotor position, rad } \\ & \text { Direct and quadrature axis flux linkages of } \\ & \text { SynRM as a function of } i_{d}, i_{q} \text { and } \theta_{r} \\ \psi_{d}, \psi_{q} & \text { respectively, V.s } \\ & \text { Direct and quadrature axis flux linkages of } \\ & \text { SynRM as a function of } i_{d} \text { and } i_{q} \text { with } \\ P F & \text { averaging to } \theta_{r} \text { respectively, V.s } \\ & \text { Motor power factor }\end{array}$

\section{INTRODUCTION}

Synchronous Reluctance Motors (SynRMs) have many $\checkmark$ attractive features compared with other types of motors. This is due to the rugged construction and the absence of rareearth magnets [1]. In addition, there are no cage, windings and magnets on the rotor. The torque per ampere is acceptable. This type of machines can withstand high temperatures as well

978-1-4799-8805-1/15/\$31.00 C2015 IEEE as high centrifugal forces: they are suitable for high speed applications in machine tools and molecular pumps[2, 3]. Moreover, the control system is similar to that of induction motor drives.

The SynRM (with a flux-barrier rotor type) behavior depends mainly on the saliency difference which is the difference between the direct and quadrature axis inductances $\left(L_{d}, L_{q}\right)$. This difference is affected by the rotor geometry design and the magnetic material steel grade type of the motor core. The magnetic material steel grade has an effect on both the $d q$-axis inductances and the core loss of the SynRM due to different permeability [4]. In addition, the rotor position with respect to the stator has an effect on the $d q$-axis inductances. Moreover, the $d q$-axis inductances do not only depend on the self-currents but also on the mutual ones due to sharing the same flux path on the rotor core. This dependency is called the cross-saturation effect. Therefore, a model considering the saturation, cross-saturation and the position effects is necessary for an accurate representation for the SynRM control and efficiency optimization $[4,5,6]$.

Several papers have been focused on the saturation and cross-saturation effects on the SynRM performance and control. Different models have been proposed to take into account the effect of the magnetic saturation for electrical machines $[7,8,9,10]$.

In [7], a saturation modelling in D-Q axis models of salient pole synchronous machines was proposed based on generalized forms tacking into account a single saturation factor with the same saturation level in both $d q$-axis inductances. In [8], the magnetic saturation effects on the control of a SynRM was studied based on a single saturation factor with measurable results assuming that the $d q$-axis inductances saturate to the same level at all the operating 
conditions. The stability limits of interior permanent magnet (IPM) motors have been investigated in [9]. Different effects of magnetic saturation has been studied. The importance of including the magnetic saturation have been prove in studying the performance of IPM motors. In [10], the impact of cross saturation in SynRM of transverse-laminated type is investigated with a mixed theoretical and experimental approach considering assumptions in the measuring of the $d q$ axis flux linkages relations.

This paper analyses deeply the influence of the magnetic saturation and rotor position effects on the transient conditions for the SynRM performance and its stability limits. A Finite Element Method (FEM) is used to obtain an accurate representation for the $d q$-axis flux linkages relations. To reduce the calculation time, a Look-up table (LUT) based on the FEM is generated to be used in the simulation of the motor behaviour at steady-state and transient conditions.

This paper is organized as follows. Section III presents the modelling of the SynRM at transient condition considering the magnetic saturation and the position effects. Afterwards, section IV deals with the transient analysis for the SynRM performance. Finally, section V presents the conclusion for the studied work.

\section{SYNRM MODELLING}

\section{A. Nonlinear dq model of SynRM}

In order to eliminate the time-varying inductances in the voltage equations, the SynRM was represented in the $d q$ - axis reference frame. This frame is fixed on the rotor, which rotates at $\omega_{\mathrm{r}}[4,11,12]$.

The $d q$-axis voltage equations can be written as:

$$
\begin{aligned}
& v_{d}=R_{s} i_{d}+p \lambda_{d}\left(i_{d}, i_{q}, \theta_{r}\right)-\omega_{r} P \lambda_{q}\left(i_{d}, i_{q}, \theta_{r}\right) \\
& v_{q}=R_{s} i_{q}+p \lambda_{q}\left(i_{d}, i_{q}, \theta_{r}\right)+\omega_{r} P \lambda_{d}\left(i_{d}, i_{q}, \theta_{r}\right)
\end{aligned}
$$

The $d q$-axis flux linkage relations are expressed as:

$$
\begin{aligned}
& \lambda_{d}\left(i_{d}, i_{q}, \theta_{r}\right)=L_{d}\left(i_{d}, i_{q}, \theta_{r}\right) i_{d} \\
& \lambda_{q}\left(i_{d}, i_{q}, \theta_{r}\right)=L_{q}\left(i_{d}, i_{q}, \theta_{r}\right) i_{q}
\end{aligned}
$$

The electromagnetic torque can be obtained as:

$T_{e}=\frac{3}{2} P\left(\lambda_{d}\left(i_{d}, i_{q}, \theta_{r}\right) i_{q}-\lambda_{q}\left(i_{d}, i_{q}, \theta_{r}\right) i_{d}\right)$

The $d q$-axis currents and voltages can be expressed as a function of current angle $(\alpha)$.

$$
\begin{aligned}
& i_{d}=I_{m} \cos (\alpha), i_{q}=I_{m} \sin (\alpha) \\
& v_{d}=-V_{m} \sin (\delta), v_{q}=V_{m} \cos (\delta)
\end{aligned}
$$

where $\alpha$ is the angle of the stator current space vector with respect to the $d$-axis of the motor as shown in Fig. 1.

The SynRM load angle $(\delta)$ can be calculated as:

$$
\delta=\mathrm{J}\left(\omega_{r}-\omega_{s}\right) d t
$$

Neglecting the stator resistance $R_{s}$, the power factor $(P F)$ of the SynRM can be expressed as a function of the saliency ratio $K=L d / L q$ :

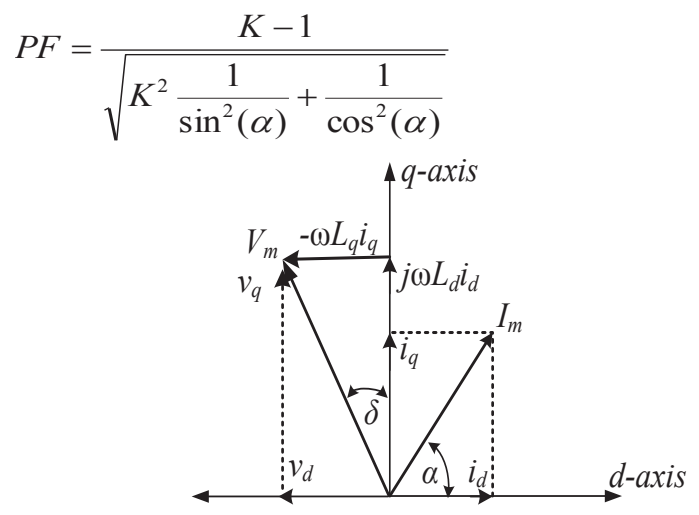

Fig. 1. SynRM vector diagram

\section{B. Finite Element Method (FEM) for the SynRM}

The $d q$-axis flux linkages $\left(\lambda_{d}\left(i_{d}, i_{q}, \theta_{r}\right), \lambda_{q}\left(i_{d}, i_{q}, \theta_{r}\right)\right)$ of the SynRM have been calculated using FEM. The SynRM has four poles with symmetrical geometry so that it is sufficient to model only a quarter of the motor geometry. The parameters of the adopted motor are specified on table I (Appendix).

Figure 2 shows the flux paths in a quarter of the adopted motor geometry using FEM.

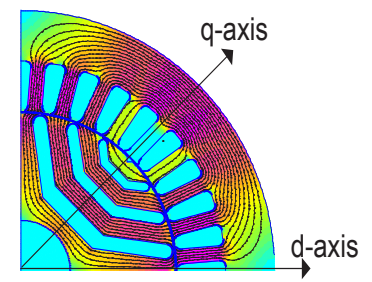

(a) $\theta_{r}=0^{\circ}$

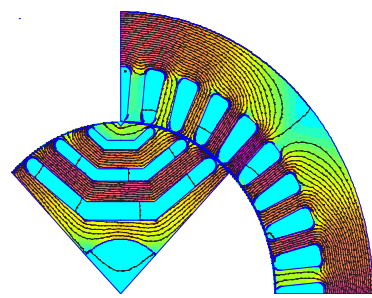

(b) $\theta_{r}=45^{\circ}$
Fig. 2. Flux paths for the adopted SynRM using FEM for a quarter geometry with different positions

To obtain the $d q$-axis flux linkages relations for the SynRM, the FEM is supplied with different $i_{d}, i_{q}$ and $\theta_{r}$ combinations for variable stator currents from 0 to the rated value $\left(I_{m}\right)$. On the one hand, Fig. 3 shows the $d$-axis flux linkage of the SynRM for a half mechanical revolution based on different $i_{d}$ and $i_{q}$. The variation of the $d$-axis flux linkage with respect to the position $\left(\theta_{r}\right)$ is shown. This is due to the variation of the magnetic reluctance between the slot and the teeth positions. It is clear from Fig. 3 that the $d$-axis flux linkage increases with increasing the $i_{d}$. In addition, the $d$-axis flux linkage decreases with increasing the $i_{q}$ by about $15 \%$ (Fig. 3-a). On the other hand, Fig. 4 shows the $q$-axis flux linkage of the SynRM for a half mechanical revolution and for different $i_{d}$ and $i_{q}$. It is obvious from Fig. 4 that the $q$-axis flux linkage increases with increasing the $i_{q}$. In addition, the effect of increasing $i_{\mathrm{d}}$ on the $q$-axis flux linkage is notable and leads to a decrease of about $50 \%$ (Fig.4-a). Hence, the effect of $i_{d}$ on the $q$-axis flux linkage is greater than the effect of $i_{q}$ on the $d$-axis flux linkage (about $35 \%)$. This is due to the higher value of $d$-axis flux linkage compared to the $q$-axis (saliency factor equals about 5 at the rated stator current).

Figure 5 shows the average $d q$-axis flux linkages of the SynRM with respect to the positon $\left(\theta_{r}\right)$. In addition, the nonlinearity of the $d q$-axis flux linkages with the currents can 
be noticed. This leads to nonlinearity characteristics of $d q$-axis inductances $\left(L_{d}, L_{q}\right)$; hence it has a strong effect on the SynRM performance.

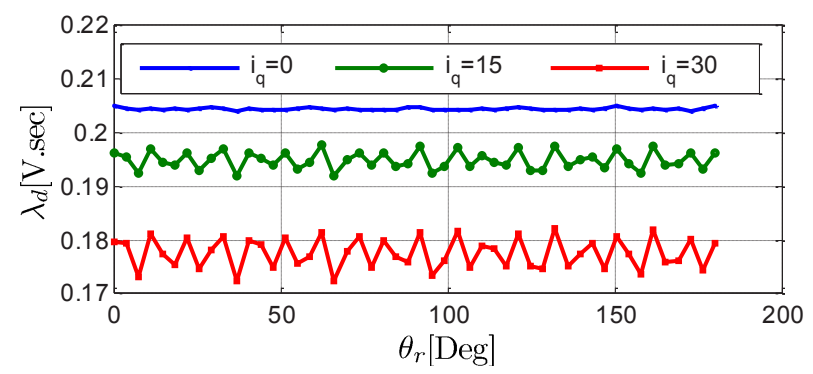

(a) $\lambda_{d}$ versus $\theta_{r}$ for constant $\mathrm{i}_{\mathrm{d}}=10 \mathrm{~A}$ and different $\mathrm{i}_{\mathrm{q}}=0,15$ and $30 \mathrm{~A}$

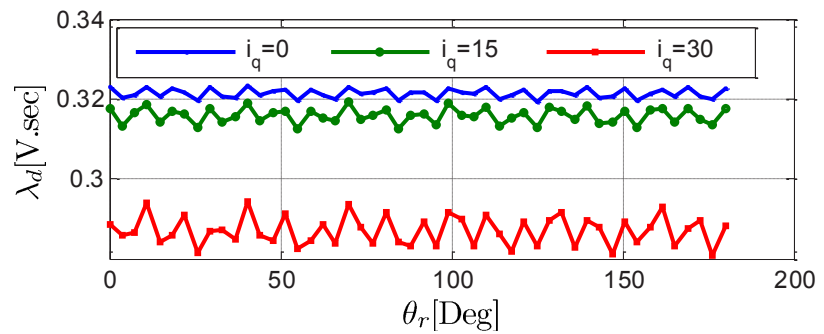

(b) $\lambda_{\mathrm{d}}$ versus $\theta_{r}$ for constant $\mathrm{i}_{\mathrm{d}}=20 \mathrm{~A}$ and different $\mathrm{i}_{\mathrm{q}}=0,15$ and $30 \mathrm{~A}$

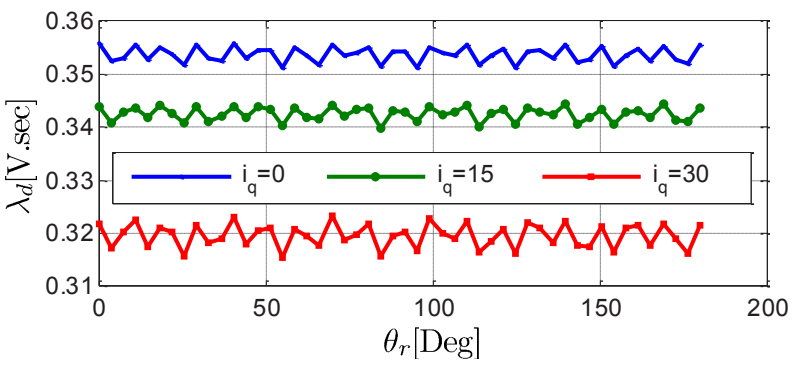

(c) $\lambda_{\mathrm{d}}$ versus $\theta_{r}$ for constant $\mathrm{i}_{\mathrm{d}}=30 \mathrm{~A}$ and different $\mathrm{i}_{\mathrm{q}}=0,15$ and $30 \mathrm{~A}$

Fig. 3. d-axis flux linkage $\left(\lambda_{d}\left(i_{d}, i_{q}, \theta_{r}\right)\right)$ for the SynRM using FEM for half mechanical revolution.

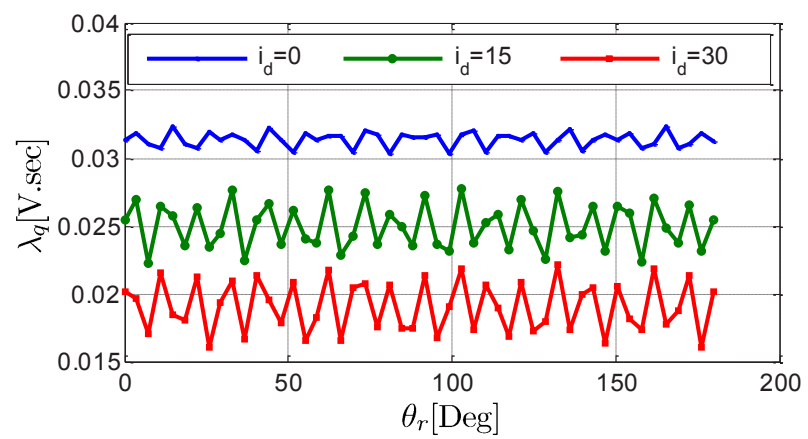

(a) $\lambda_{q}$ versus $\theta_{r}$ for constant $\mathrm{i}_{\mathrm{q}}=10 \mathrm{~A}$ and different $\mathrm{i}_{\mathrm{d}}=0,15$ and $30 \mathrm{~A}$

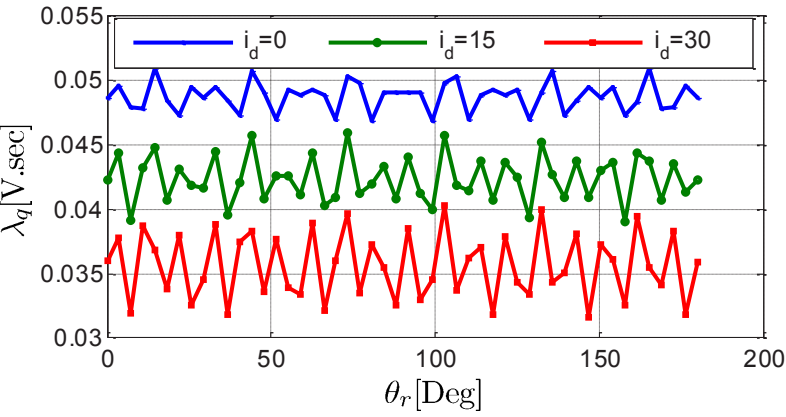

(b) $\lambda_{q}$ versus $\theta_{r}$ for constant $i_{q}=20 \mathrm{~A}$ and different $\mathrm{i}_{\mathrm{d}}=0,15$ and $30 \mathrm{~A}$

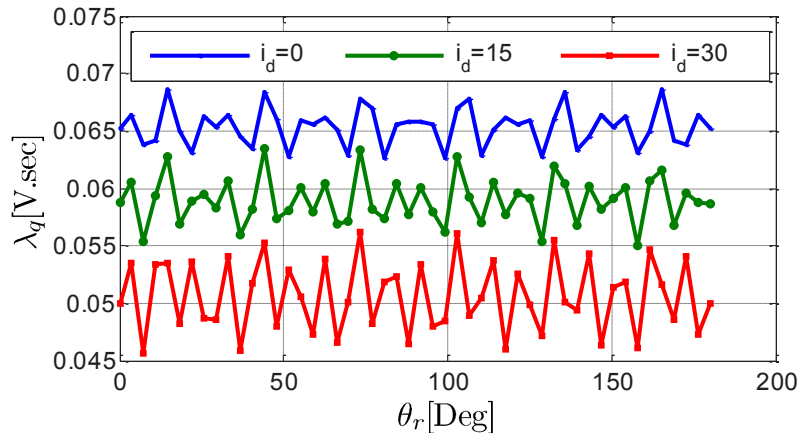

(c) $\lambda_{\mathrm{q}}$ versus $\theta_{r}$ for constant $\mathrm{i}_{\mathrm{q}}=30 \mathrm{~A}$ and different $\mathrm{i}_{\mathrm{d}}=0,15$ and $30 \mathrm{~A}$

Fig. 4. q-axis flux linkage $\left(\lambda_{q}\left(i_{d}, i_{q}, \theta_{r}\right)\right)$ for the SynRM using FEM for half mechanical revolution.

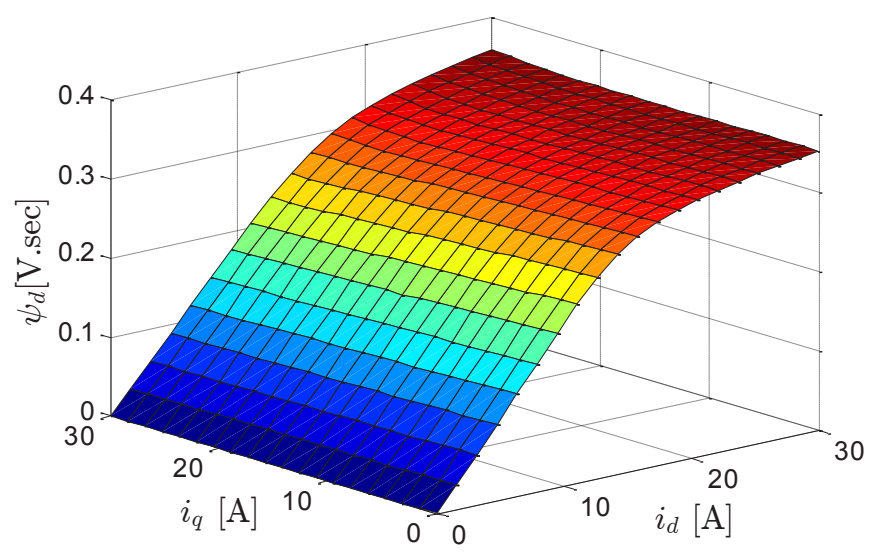

(a) d-axis flux linkage $\left(\psi_{\mathrm{d}}\left(\mathrm{i}_{\mathrm{d}}, \mathrm{i}_{\mathrm{q}}\right)\right)$

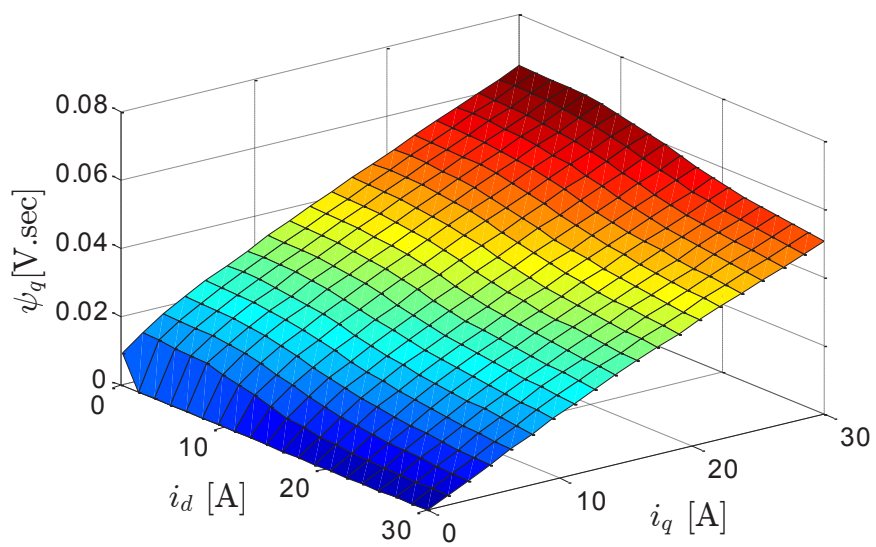

(b) q-axis flux linkage $\left(\psi_{\mathrm{q}}\left(\mathrm{i}_{\mathrm{d}}, \mathrm{i}_{\mathrm{q}}\right)\right)$

Fig. 5. (a) d-axis flux linkage $\left(\psi_{\mathrm{d}}\left(\mathrm{i}_{\mathrm{d}}, \mathrm{i}_{\mathrm{q}}\right)\right)$ and $(b) \mathrm{q}$-axis flux linkage $\left(\psi_{\mathrm{q}}\left(\mathrm{i}_{\mathrm{d}}, \mathrm{i}_{\mathrm{q}}\right)\right)$ for the SynRM using FEM with averaging for the position $\left(\theta_{\mathrm{r}}\right)$.

\section{TRANSIENT-STATE ANALYSIS FOR THE SYNRM}

In order to study the effect of the magnetic saturation and the position on the transient operation of the SynRM, a dynamic model for the SynRM based on the FEM has been solved for different conditions. Three different cases are considered; (1) the general and more accurate modeling for the SynRM where the effect of the magnetic saturation and the position are taken into account, (2) the magnetic saturation effect is considered only without the position effect, and (3) the unsaturated case where the $L_{d}$ and $L_{q}$ are considered to be constant values. From Fig. 5, it can be deduced that there are 
different values for $L_{d}$ and $L_{q}$ based on the currents. So the values of $L d$ and $L q$ set to be $L_{\mathrm{d}}=0.0185 \mathrm{H}$ and $L_{q}=0.003 \mathrm{H}$ to represent an average values for the constant inductance case with neglecting the magnetic saturation and the position effects.

Figure 6 shows the run-up response of the SynRM for different loads. On the one hand, the oscillation on the torque waveform are mainly due to the position dependence of $\lambda_{d}$ and $\lambda_{q}$. This can be understood by comparing with the torque wave form where the position effect is removed, i.e where $\lambda_{d}$ and $\lambda_{\mathrm{q}}$ are averaged over $\theta_{r}$.
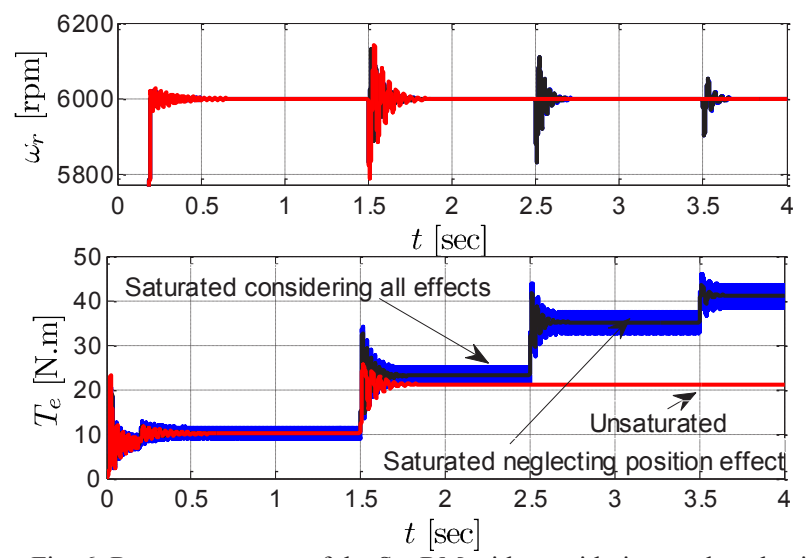

Fig. 6. Run-up response of the SynRM with considering and neglecting saturation for different loads

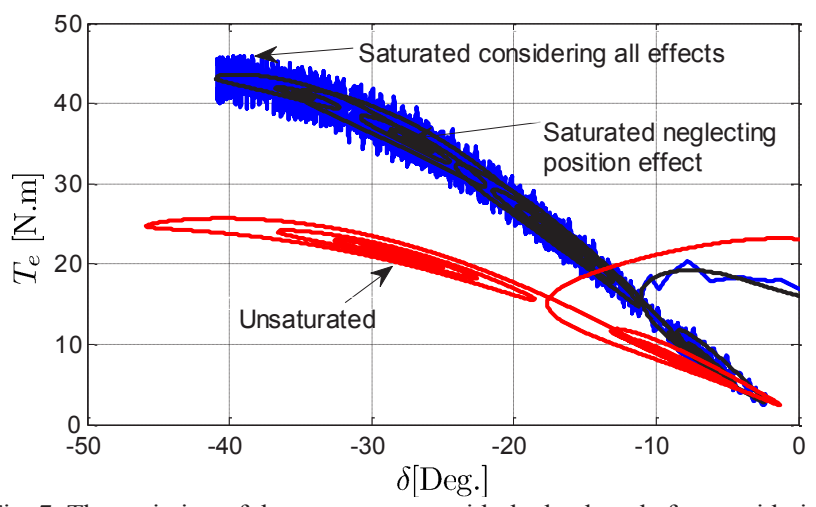

Fig. 7. The variation of the motor torque with the load angle for considering and neglecting saturation

On the other hand, it is clear that the motor torque capability increases when considering the saturation factors. The motor torque stability region can be increased from about 21 N.m with neglecting the saturation effect to about 42 N.m with including the saturation factors. This is obvious also in Figs. 7 and 8. Figure 7 shows the transient variation of the motor torque with the load angle for considering and neglecting the saturation effect. The minor loops on Fig. 7 are due to the step change of the load. Figure 8 shows the load angle and the maximum stator current for different loads in considering and neglecting the saturation effect. The variation of the power factor for considering and neglecting the saturation effect can be seen from Fig. 9. It can be noted that the power factor of the saturated case is higher than the unsaturated one. This is due to the dependency of the power factor on saliency ratio $\left(L_{d} / L_{q}\right)$ of the motor.
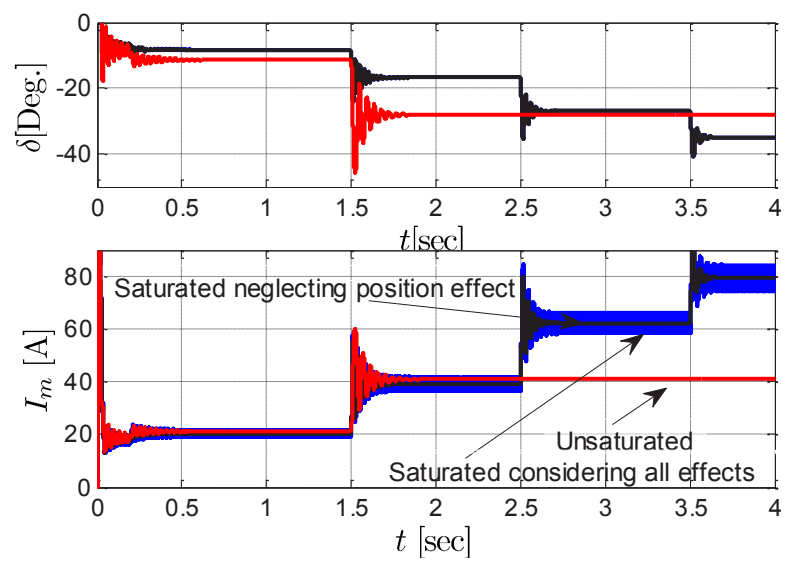

Fig. 8. The variation of the load angle and the maximum stator current of the SynRM with considering and neglecting saturation for different loads

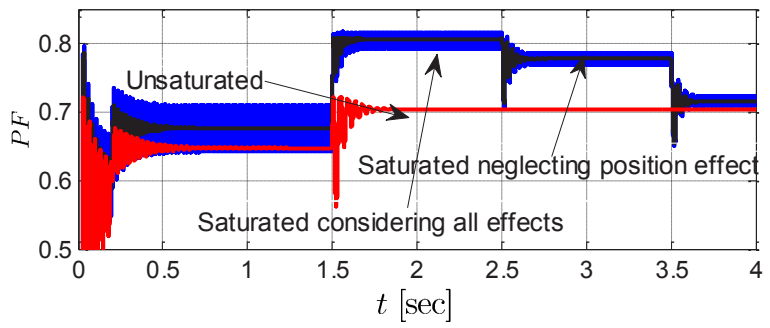

Fig. 9. The variation of the power factor of the SynRM with considering and neglecting saturation for different loads

\section{CONCLUSION}

This article has presented the influence of the magnetic saturation on the SynRM performance at transient conditions. Moreover, the stability limits of operation for the adopted motor have been investigated. The $d q$ - axis flux linkages of the motor considering the magnetic saturation and the position effects have been calculated using FEM. In order to reduce the calculation time of the FEM, a look-up table (LUT) is generated based on the FEM calculation to be used on the simulation for the SynRM characteristics at dynamic conditions. On the one hand, it's noted that the $d$-axis flux linkage varies linearly with $i_{d}$ at lower values for $i_{d}$ about half of the rated value and then becomes saturated with increasing $i_{d}$. On the other hand, $q$-axis flux linkage varies linearly with $i_{q}$. The effect of $i_{q}$ on the $d$-axis flux linkage is very small compared to the effect of $i_{d}$ on the $d$-axis. The variation on $q$ axis flux linkage has a great impact on the SynRM performance and its stability limits.

The magnetic saturation increases the SynRM stability operation region and the torque capability by about $200 \%$ compared with the unsaturated case.

Finally, the results show the importance of including the magnetic saturation on the modeling of the SynRM performance and its stability limits. 
APPENDIX

TABLE I

SYNRM PARAMETERS

\begin{tabular}{|l|c|}
\hline \multicolumn{1}{|c|}{ Parameter } & Value \\
\hline Number of pole pairs & 4 \\
Number of rotor flux barriers per pole & 3 \\
Number of stator slots & 36 \\
Number of phases & 3 \\
Stator outer diameter & $180 \mathrm{~mm}$ \\
Stator inner diameter & $110 \mathrm{~mm}$ \\
Rotor outer diameter & $109.4 \mathrm{~mm}$ \\
Rotor shaft diameter & $35 \mathrm{~mm}$ \\
Axial length & $140 \mathrm{~mm}$ \\
Air gap length & $0.3 \mathrm{~mm}$ \\
Rated speed & $6000 \mathrm{RPM}$ \\
Rated frequency & $200 \mathrm{~Hz}$ \\
Rated current & $22 \mathrm{~A}$ \\
Rated voltage & $380 \mathrm{~V}$ \\
Stator resistance & $0.15 \Omega$ \\
Moment of inertia & $0.0025 \mathrm{Kg} \cdot \mathrm{m}^{2}$ \\
\hline
\end{tabular}

\section{ACKNOWLEDGEMENT}

The authors acknowledge the Egyptian Ministry of Higher Education (Cultural Affairs and Missions Sector) and Special Research Fund of Ghent University (BOF) for the financial support during this work.

\section{REFERENCES}

[1] S. Taghavi, and P. Pillay, "A sizing methodology of the synchronous reluctance motor for traction applications," IEEE J. Emerg. Sel. Topics Power Electron. vol. 2 no. 2, pp. 329-340, Jun. 2014.

[2] E. Daryabeigi, H. Abootorabi Zarchi, G. R. Arab Markadeh, J. Soltani, and F. Blaabjerg, "Online MTPA control approach for synchronous reluctance motor drives based on emotional controller," IEEE Trans. Power Electronic. vol. 30, no. 4, pp. 2157-2166, Apr. 2015.

[3] M. Nabil, S. M. Allam and E. M. Rashad, "Performance improvement of a photovoltaic pumping system using a synchronous reluctance motor," Electric Power Components and Systems Journal, vol. 41, no. 4, pp. 474-464, Jan. 2013.

[4] M. N. Ibrahim, P. Sergeant and E. M. Rashad, "Synchronous reluctance motors performance based on different electrical steel grades," IEEE Trans. Mag. vol. 51, no. 11, pp.1-4, Nov. 2015.

[5] Shu Yamamoto, Takahiro Ara, and Kouki Matsuse, "A Method to calculate transient characteristics of synchronous reluctance motors considering iron loss and cross-magnetic saturation," IEEE Trans. Ind. Appl., vol. 43, no. 1, pp. 47-56, Jan./Feb. 2007.

[6] M. Ferrari, N. Bianchi, and E. Fornasiero, "Analysis of rotor saturation in synchronous reluctance and PM-assisted reluctance motors," IEEE Trans. Ind. Appl., vol. 51, no. 1, pp. 169-177, Jan./Feb. 2015.

[7] E.Levi, "Saturation modelling in D-Q axis models of salient pole synchronous machines," IEEE Trans. Energy Convers. vol. 14, no. 1, pp. 44-50, Mar. 1999.

[8] Thierry Lubin, Hubert Razik, and Abderrezak Rezzoug, "Magnetic saturation effects on the control of a synchronous reluctance machine," IEEE Trans. Energy Convers. vol. 17, no. 3, pp. 356-362, Sept. 2002.

[9] E. M. Rashad, "Stability Limits of Saturated Interior Permanent Magnet Motors," in conf. Power Electronics and Drives Systems, Kuala Lumpur, 2005, pp. 584 - 589.

[10] A. Vagati, M. Pastorelli, F. Scapino, and G. Franceschini, "Impact of cross saturation in synchronous reluctance motors of the transverse laminated type," IEEE Trans. Ind. Appl., vol. 36, no. 4, pp. 1039-1046, Jul./Aug. 2000.

[11] A. Kilthau and J. M. Pacas, "Parameter-measurement and control of the synchronous reluctance machine including cross saturation," in Conf. Rec. IEEE-IAS Annu. Meeting, Sept.-Oct. 2001, vol. 4, pp. 2302-2309.

[12] Gorazd Stumberger, Bojan Stumberger, and Drago Dolinar, "Identification of linear synchronous reluctance motor parameters," IEEE Trans. Ind. Appl., vol. 40, no. 5, pp. 1317-1324, Sept./Oct. 2004.

\section{AUTHORS' INFORMATION}

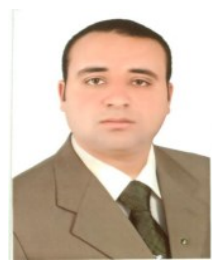

Mohamed N. Ibrahim was born in Kafrelshiekh, Egypt on September 18, 1986. He has graduated from Faculty of Engineering, Kafrelshiekh University, Egypt on 2008. $\mathrm{He}$ received his MSc. degree in Electrical Power and Machines Engineering from Tanta University in 2012. Since 2012, he is working as an assistant lecturer at the Department of Electrical Engineering, Faculty of Engineering, Kafrelshiekh University, Egypt.

$\mathrm{He}$ is currently working towards the $\mathrm{PhD}$ at Ghent University, Belgium in cooperation with Tanta University, Egypt. His research interests are in Electrical Machines, Electrical Drives, Power Electronics and Renewable Energy Systems.

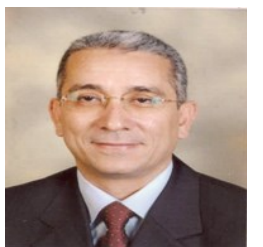

Prof. Essam M. Rashad was born in Shebin ElKom, Egypt in 1960. He received his BSc degree from the department of Electric Power and Machines Engineering., Faculty of Engineering, Shebin ElKom, Menoufiya University, Egypt in May 1983. In 1987 and 1992 he received $\mathrm{MSc}$ and $\mathrm{PhD}$, respectively both from faculty of Engineering Alexandria university, Egypt. From 1985 to 1990, he was an offshore electrical engineer in Belayim Petraulem Company, Egypt. In 1992 he has joined Faculty of Engineering, Tanta University, Egypt, where he is currently a Professor and Head of Electrical Power and Machines Engineering. From Feb. to Aug 2000, he was a visiting researcher in Faculty of Engineering, Nagasaki University, Japan. In summer 2003, he was a visiting researcher at Faculty of Engineering and Applied Science, Memorial University of Newfoundland, St. John's, NL, Canada. From 2004 to 2009, he was Head of Electrical Technology Department, Buraydah College of Technology, Kingdom of Saudi Arabia. From 2011 to 2014, he was Vice Dean for Education and Student affairs of Faculty of Engineering, Tanta University, Egypt.

Prof. Rashad research interests include electrical machine analysis and design, electrical drives, power electronics and renewable energy systems.

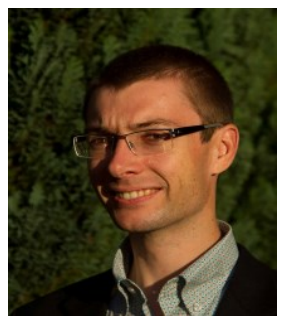

Peter Sergeant received the M.Sc. degree in electromechanical engineering in 2001, and the $\mathrm{Ph} . \mathrm{D}$. degree in engineering sciences in 2006, both from Ghent University, Ghent, Belgium.

In 2001, he became a researcher at the Electrical Energy Laboratory of Ghent University. He became a postdoctoral researcher at Ghent University in 2006 (postdoctoral fellow of the Research Foundation - Flanders) and at Ghent University College in 2008. Since 2012, he is associate professor at Ghent University. His current research interests include numerical methods in combination with optimization techniques to design nonlinear electromagnetic systems, in particular, electrical machines for sustainable energy applications. 